\title{
Peter Swann's Key Role in the Past, Present and Future of Dynamic In-situ TEM
}

Edward D Boyes ${ }^{1,2,3}$, Pratibha L Gai ${ }^{1,2,4}$ and Archie Howie ${ }^{1,5}$

York JEOL Nanocentre $^{1}$ and Departments of Physics ${ }^{2}$, Electronics ${ }^{3}$ and Chemistry ${ }^{4}$, University of York, York, YO10 5DD, UK

Cavendish Laboratory ${ }^{5}$, University of Cambridge, J J Thomson Avenue, Cambridge, CB3 OHE, UK

The breadth of vision combined with meticulous attention to detail which characterized Peter Swann's contributions to electron microscopy can be detected in his $\mathrm{PhD}$ work on stacking faults. He studied the influence of stacking fault energy on the dislocation arrangements and plasticity in deformed copper alloys, becoming acutely aware that the standard stereo-viewing cartridge with a single-axis of tilt of only about $4^{0}$ was woefully inadequate for systematic diffraction contrast imaging. Nevertheless one aspect of a broader vision was realized when his measurements of stacking fault energy in Hume Rothery alloys [1] showed that this depended mostly on the valence electron density. Not content with this bridge between mechanical and electronic properties, Peter boldly suggested that stacking faults could provide a link to chemistry through their role in the critical problem of stress corrosion cracking (SCC). The motivation to develop and imaginatively deploy instrumentation ranging from goniometers to full-blown microscopy systems for in-situ chemistry was therefore in place.

After a few years at US Steel in Pittsburgh, where his first goniometer was developed, Peter returned to Imperial College and became involved in the UK HVEM program. The opportunity he found to design and build a variety of sophisticated specimen stages for this community together with the first incarnation of the Gatan company was later brilliantly described by him [2]. Peter's "pioneering work in promoting in-situ stage design and experimentation" was however gratefully acknowledged much more quickly in an influential account of the already long history of in-situ TEM [3].

This history goes in several directions, (a) better vacuum for deposition or sample modification under more controlled near-UHV conditions [4,5], (b) studies of reactive samples avoiding contact with the air by conventional sample loading, generally by in-situ preparation [6], (c) liquid environments to retain hydration [7], including of biomaterials, and to study structural transformation under stimuli, both chemical and electrical, (d) gas reaction studies [8], especially to characterize quantitatively key catalyst reaction sequences and to identify intermediate reaction species which may be metastable with respect to conditions of gas environment and/or temperature, and therefore not reliably accessible in discontinuous or ex-situ studies, but important to understanding reaction mechanisms and thereby to establish critical catalyst design criteria [9,10], and (e) irradiation studies using the e-beam or ions [11].

Peter Swann made revolutionary advances in many of these areas. In (d), his fully functional 4-aperture differentially pumped system and attendant custom-built hot stage [12] developed for the AEI EM7 HVEM most notably overcame the pressure limitation of earlier systems [8] and critically introduced useful specimen tilt. With this equipment he was able to follow technologically important processes such as the reduction of haematite to iron [13]. He did not take his eye off the ball of SCC but had to content himself with detailed study of the cracks formed after transfer to the HVEM from a separate reaction chamber [14]. Under (e) he studied some of the beam-induced knock-on irradiation processes occurring in the HVEM including the electron beam induced aqueous oxidation of silicon [15]. 
Electron microscopy development by the main instrument manufacturers has targeted improvements towards atomic resolution and sensitivity of analysis, with static samples often created for microscopy. But the true value of the tools lies in addressing problems of significant societal importance where it is often a crucial challenge to be able to prepare a suitable specimen and to study its structure and behavior under realistic conditions. Gatan have played a major role here not only with the goniometers already mentioned but also in the development of ion thinning equipment and other specialized accessories for making thin samples from bulk material. Occasionally more extensive developments were pursued such as the UHV system for the Philips/FEI 300kV EM430 [5].

Peter's early ETEM system was developed further by Gai and Doole at Oxford leading to key classical g.b analyses of crystal defects and critical understanding of the atomic scale microstructural basis of catalyst properties, including activation, activity, selectivity, deactivation and recovery of complex oxide catalysts for commercial hydrocarbon oxidation [9,10]. At Oxford and DuPont [16] further progress was made in designing an integrated system to fit higher resolution modern instruments [10] and this is now used in commercial machines dedicated to the ETEM mode. The most recent equipment developed at York has $0.1 \mathrm{~nm}$ image resolution in both ESTEM and ETEM and a full array of imaging and analytical methods $[17,18,19]$. The ESTEM uses redesigned Gatan hot stages and DENS MEMS technology. These both retain the full single atom sensitive performance of the core instrument with full gas modifications and pumping systems operational for fundamental reaction mechanism studies [19].

SCC continues to be a phenomenon of great technological importance particularly for the stainless steel components used in reactors and storage vessels. Although the influence of slip planes on the crack morphology is well demonstrated [14], the precise significance of the stacking fault energy in austenitic stainless steels is not clear. Nevertheless the stacking fault energy continues to be one of the input parameters in formulae simulating the corrosion sensitivity. The need to realize Peter Swann's dream of atomic resolution, in-situ SCC studies in boiling $\mathrm{MgCl}_{2}$ is therefore still here to challenge us.

\section{References}

[1] A Howie and P R Swann, Phil Mag, (1961) 6, p1215

[2] P R Swann in 'Materials Science and Engineering; Its Nucleation and Growth' ed M McLean pub Woodhouse press, (2002) p53

[3] E P Butler and K F Hale, 'Dynamic Experiments in the Electron Microscope', pub North Holland, 1981

[4] Y Kondo, K Takayanagi et al, Ultramicroscopy (1991) 35, p111

[5] D J Smith, P R Swann et al, Ultramicroscopy, (1993) 49, p26

[6] D A Goulden, Phil Mag, (1976) 33, p393

[7] D D Double, A Hellawell and S J Perry, Proc Roy Soc, (1978) A359, p435

[8] H Hashimoto, T Naikui, T Etoh and K Fujiwara, Jap J Appl Phys, (1968) 7, p946

[9] P L Gai, et al, Nature (1990) 348, p430; and J. Solid St. Chem. (1983) 49, p25.

[10] P L Gai et al, Science (1995) 267, p661

[11] B L Eyre et al, Phil Mag (1971) 23, p439

[12] P R Swann and N Tighe, Jernkont. Ann, (1971) 155, p497

[13] P R Swann and N Tighe, Metall. Trans. B Process Metallurgy (1977) 8, p479

[14] G M Scamans and P R Swann, Corrosion Science (1978) 18, p983

[15] H M Flower and P R Swann, Corrosion Science (1977) 17, p305

[16] E D Boyes and P L Gai, Ultramicroscopy, (1997) 67, p219

[17] E D Boyes, M Ward, L Lari and P L Gai, Ann. Phys. (Berlin), (2013) 525, p423

[18] J Sagar, L Fleet, M Walsh, L Lari, E D Boyes, O Whear, T Huminiuc and A Hirohata, Applied Physics Letters, (2014) 105, 032401

[19] P L Gai, L Lari, MR Ward and E D Boyes, Chem. Phys. Lett. (2014) 592, p335 